\title{
Influence of temperament on the professionalism of firefighters
}

\author{
$A$ Belousova ${ }^{1, *}, A$ Osipov $^{2}$, and $V$ Ermak $^{3}$ \\ ${ }^{1}$ Don State Technical University, Gagarin sq, 1, Rostov- on-Don, 344003, Russia \\ ${ }^{2}$ Ministry of Emergency Situations for Republic of North Ossetia - Alania, Vladikavkaz, st. \\ International, 1, 362045, Russia \\ ${ }^{3}$ Don Institute Psychoanalytic and Psychodramatherapeutic Research, Krasnoarmeyskaya str., 108, \\ Rostov- on-Don, 344082, Russia
}

\begin{abstract}
The article discusses the features of temperament and its indicators in firefighters of different groups of professionalism. Temperament is understood in accordance with the formal-dynamic concept of V. M. Rusalov, which highlights the formal-dynamic properties of the individual: ergic, plasticity, speed, emotionality. The sample consisted of 210 firefighters, divided into three groups of professionalism: firefighters-mentors, firefighters of the 1st class, firefighters of the 2nd class. A questionnaire for determining V. M.'s temperament was used. Rusalova, methods of mathematical statistics: the Kruskal-Wallace method and ANOVA analysis of variance. The features of the development of temperament indicators in various groups of firefighters are revealed. The main results of the study are described, indicating that there are indicators (social tempo, tempo, social ergicity, ergicity) that are common to all groups of firefighters. At the same time, some indicators of temperament (social plasticity and emotionality) differ in severity in certain groups of firefighters: social plasticity dominates in class 2 firefighters, and emotionality - in class 1 firefighters.
\end{abstract}

\section{Introduction}

When considering the profession of a firefighter, it is necessary to understand that it imposes high requirements on specialists. If we consider the work of firefighters from a psychological point of view, we can see that it is associated with a lot of emotionality due to the peculiarities of their activities: continuous neuropsychic stress caused by systematic work in an unusual environment (at high temperatures, high concentrations of smoke, limited visibility, etc. Gorenje, etc.), a constant threat to life and health (possible collapse of burning structures, explosions of vapors and gases, poisoning with toxic substances released as a result of burning), negative emotional effects (removal of injured and burned people, etc.) [1-3]; heavy physical loads associated with the dismantling of structures and equipment, laying of hose lines, work with fire and rescue equipment for various purposes, removal of material values, high work rate, etc. [1-3]; the need to maintain intensity and concentration of attention in order to monitor changes in the fire situation, keep in view the

*Corresponding author: belousovaak@gmail.com 
state of numerous structures, technological units and installations in the process of performing a combat task on a burning object; difficulties caused by the need to work in a limited space (in tunnels, underground galleries, gas and cable communications), which complicates actions, violates the usual methods of promotion, working poses (crawling, lying down, etc.) [4-5]; high responsibility of each firefighter with relative independence of actions and decisions to save lives, expensive equipment, etc.; the presence of unexpected and sudden obstacles that complicate the performance of combat tasks [1-6].

According to many scientists [2, 5-7], a special profile of professionally important qualities of an employee is desirable for this profession, which we can attribute to individual and personal characteristics acquired in the course of professional activity. In accordance with a common point of view [8-10], we can divide the fire into two groups. The first group includes firefighters with a strong nervous system, not anxious and prone to risk, which is characterized by a low increase in indicators of mental tension in extreme conditions. In this group, stress has a positive effect on the effectiveness of actions. The second group includes firefighters with a weak nervous system, anxious, not prone to risk, which is characterized by an increase in indicators of mental tension in extreme conditions. In this case, a high level of stress negatively affects the effectiveness of actions, even to the point of refusing to complete the task.

Thus, based on the analysis, it can be assumed that the profession of a firefighter belongs to the type in which the requirements of the profession (strong physical activity, work with victims and victims, etc.) can be met by people who have special individual qualities (developed adaptation, strong nervous system). These qualities include temperament.

According to the definition of J. Strelau, temperament is a set of formal and relatively stable behavior characteristics that are manifested in the energy level of behavior and in the time parameters of reactions [8-9]. Temperament manifests itself in actions regardless of their content and orientation, and not only in emotional reactions, as many researchers claim, but also in intellectual actions. Temperament, due primarily to the functioning of complex physiological mechanisms, affects human actions and reactions in two main dimensions: the energy level and the temporal characteristics of behavior - and therefore serves as one of the regulatory mechanisms of activity. It is a certain predisposition or stable feature, due to which mental or psychomotor phenomena occur more easily or more difficult, slower or faster, weaker or stronger, and so on. The properties of temperament in comparison with other mental characteristics are among the most constant and unchangeable. At present, extensive empirical material has been accumulated that indicates the relative stability of these properties [8-9].

In Russia, V. M. Rusalov develops the ideas outlined by Ya Strelyau. V. M. Rusalov [10] believes that there are two levels in a person's personality, two different aspects of personal properties - formal-dynamic and meaningful. Content properties are the product of education and socialization, covering not only knowledge, skills, but also intelligence, character, attitudes, meanings, and so on. At the same time, people have certain stable qualities, such as temperament, personality traits. As the main element of V. M.'s personality. Rusalov identifies four main formal and dynamic personality traits: ergic - the level of mental stress, endurance; plasticity - the ease of switching from one behavior program to another; speed - the individual pace of behavior; emotional threshold-sensitivity to feedback, to the discrepancy between real and planned behavior.

The dependence of activity efficiency on the properties of the nervous system has long been known $[5,11]$. The state of stress that occurs in firefighters in extreme conditions sharply worsens the actions of persons with a weak nervous system and does not affect people with a strong nervous system $[5,11]$. 
According to a number of scientists $[5,11]$, adverse conditions, especially if they take a long, prolonged character, or following one after another circumstances that cause negative emotions, lead to stress and the subsequent development of post-traumatic stress disorder $[5,11-12]$.

The necessary mental properties of a person develop in the course of their professional activity or are compensated by other properties using special techniques and methods of action [11-12]. Only in extreme and extreme cases, such as fires, do the requirements for individual mental properties increase dramatically, while many compensation mechanisms fail to work. And if the professional activity is such that an extreme situation occurs it often enough, there is a need in screening the people that do not meet psychological properties to the requirements of the activity or in the redistribution of their jobs based on individual psychological qualities [2-7, 11-12].

We assume that the professional activities of fire lead to the development of their individual psychological qualities, including qualities of temperament, which are the determinants of the effectiveness of professional activities.

\section{Materials and Methods}

Psychological research was conducted among fire and rescue units in North Ossetia-Alania. The sample consisted of the following categories of employees of the Ministry of emergency situations: the first group - firefighters-mentors with the first category of class mentor (service experience from 8 to 10 years), 57 people; the second group-firefightersrescuers with the second category of class (service experience from 3 to 5 years), 66 people; the third group - firefighters-rescuers who are undergoing training, the purpose of which is to obtain admission to participate in emergency rescue operations (service experience from 3 months to 1 year), who are at the stage of training for the profession, 87 people. A total of 210 people participated in the study.

The study of temperament properties was conducted using the V. M. Rusalov questionnaire [13], which includes the following scales: ergicity, plasticity, tempo, and emotionality. Each scale has two sub-scales: subject-oriented and subjective-oriented (or communicative). Indicators on these scales reflect two areas of human interaction with the environment: the subject world and society, that is, activities and communication.

"Ergicity" - subject ergicity characterizes the level of a person's need to master the subject world, the thirst for activity, the desire for mental and physical labor, the degree of involvement in work. "Social ergicity" - reflects the level of need for social contacts, indicates a focus on the development of social forms, activities, the desire for leadership, sociability and involvement in social activities.

"Plasticity" is an indicator of the degree of ease of switching from one subject to another, the speed of transition from one way of thinking to another in the process of interacting with the subject environment, and the desire for a variety of forms of subject activity. "Social plasticity" - helps to find out the degree of ease or difficulty of switching attention in the process of communication from one person to another, the tendency to a variety of communication programs and ready-made forms of social contact.

"Tempo" represents the speed characteristics of a person, indicates the speed of performing individual operations, the speed of motor-motor acts when performing subject activities. "Social tempo" - sets the speed characteristics of speech-motor acts in the process of communication.

"Emotionality" - evaluates emotional sensitivity to the discrepancy between the planned, expected, planned results of a real object action, sensitivity to failures in work. "Social emotionality" shows emotional sensitivity in the communication sphere: sensitivity to failures in communication, to the assessments of other people. 
Mathematical processing of the obtained data was carried out using the computer program "SPSS 21", which provides the calculation of descriptive statistics, the KruskalWallace criterion, and ANOVA analysis of variance [14].

\section{Results}

In accordance with the main objectives of the study was the analysis of the individual psychological characteristics (temperament) of the three experimental groups, the results are provided in table 1. Analysis of tabular data allows to conclude that all three studied groups observed the same profile of expression of properties of temperament, ie are practically not observed differences (figure 1).

Table 1. Average values of $\mathrm{p}$ temperament (according To V. M. Rusalov).

\begin{tabular}{|l|c|c|c|c|c|c|c|c|}
\hline $\begin{array}{l}\text { Propertie } \\
\mathbf{s}\end{array}$ & $\begin{array}{c}\text { Ergicit } \\
\mathbf{y}\end{array}$ & $\begin{array}{c}\text { Social } \\
\text { ergicit } \\
\mathbf{y}\end{array}$ & $\begin{array}{c}\text { Plastici } \\
\mathbf{t y}\end{array}$ & $\begin{array}{c}\text { Social } \\
\text { plastici } \\
\mathbf{t y}\end{array}$ & $\begin{array}{c}\text { Temp } \\
\mathbf{0}\end{array}$ & $\begin{array}{c}\text { Socia } \\
\mathbf{1} \\
\text { temp } \\
\mathbf{0}\end{array}$ & $\begin{array}{c}\text { Emotionali } \\
\text { ty }\end{array}$ & $\begin{array}{c}\text { Social } \\
\text { emotionali } \\
\text { ty }\end{array}$ \\
\hline $\begin{array}{l}\text { Firefighter } \\
\text { s-mentors }\end{array}$ & 6.37 & 8.54 & 5.61 & 3.39 & 8.84 & 6.49 & 3.09 & 3.53 \\
\hline $\begin{array}{l}\text { Firefighter } \\
\text { s class 1 }\end{array}$ & 6.39 & 8.94 & 5.83 & 3.53 & 8.71 & 6.23 & 4.47 & 4.12 \\
\hline $\begin{array}{l}\text { Firefighter } \\
\text { s class 2 }\end{array}$ & 6.54 & 8.08 & 6.14 & 4.20 & 9.29 & 6.05 & 3.32 & 3.64 \\
\hline $\begin{array}{l}\text { Kruskal- } \\
\text { Wallace } \\
\text { test }\end{array}$ & 0.088 & 5.558 & 1.168 & $8.802^{*}$ & 1.883 & 1.344 & $9.169^{*}$ & 2.202 \\
\hline ANOVA & 0.957 & 0.062 & 0.558 & 0.012 & 0.390 & 0.511 & 0.010 & 0.333 \\
\hline
\end{tabular}

\section{$\square$ Firefighters-mentors $\quad$ aFirefighters Class $1 \quad$ aFirefighters class 2}

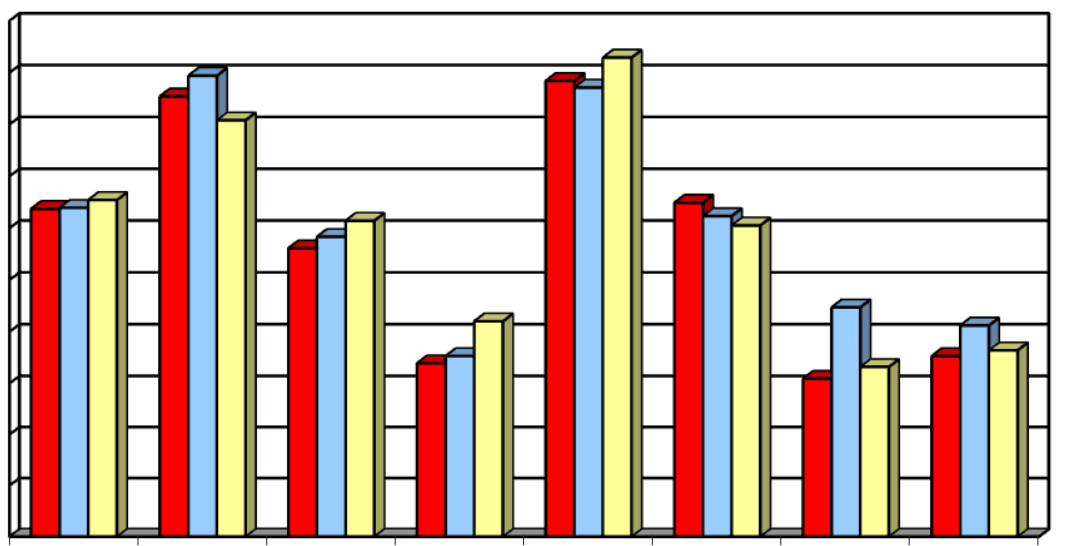

Ergicity Soc erg PlasticitySoc plast Tempo Soc temp Emot Soc

emotion

Fig. 1. Profile of temperament properties of different groups of firefighters.

Analysis of graphs and tabular data suggests that the structure of temperament properties in the three groups represented is dominated by such properties as tempo, social 
ergicity, ergicity, and social tempo. These properties show high speed characteristics of a person, speed of motor-motor reactions (due to the requirements of the profession), as well as a focus on social contacts, the development of social forms and a General high need to master the subject world, thirst for activity, and are characteristic of people with a strong nervous system. Thus, it can be argued that the requirements of professional activity and the work itself in fire and rescue formations imply professional selection of class 2 firefighters based on such temperament properties as tempo, social ergicity, ergicity, and social tempo. In other words, for people working in fire and rescue formations, subsequent professional development is associated with the development of these individual properties.

The results obtained may indicate that similar requirements on the part of professional activity contribute, on the one hand, to the professional selection of people with certain temperament properties, and on the other hand, professional development of a person deepens and improves the expression of temperament properties.

V. M. Rusalov [10] believes that formal-dynamic and content aspects can be distinguished in the human psyche. As a result of generalization of psychophysiological components, due to the innate constancy of individually stable components, regardless of specific motives, goals, etc., a formal-dynamic aspect is formed. Temperament as a component of the formal-dynamic organization of a person acts as a necessary condition and prerequisite for the formation of more highly organized levels of human organization. The content aspect is formed during the interaction of a person with the objective world and its social environment and includes subject-semantic structures (knowledge, motives, goals, etc.).

These ideas of V. M. Rusalov about two aspects of the human psyche allowed us to turn to the analysis of temperament properties as the basis for the formation of more complex personal properties. Analysis of the results showed that young (class 2 firefighters), experienced employees and fire instructors have the most developed temperament properties: tempo, social ergicity, ergicity, social tempo.

Thus, the conducted research has shown that the structure of professionally important qualities related to the requirements of the activity includes certain temperament properties that create the specifics of the type of personality in the structure of the professional personality. These include: tempo social arginate, arginate, social pace.

At the same time, the professional development of a person assumes that some properties become more pronounced, they develop in the course of professional activity that requires a person to train certain qualities (figure 2).

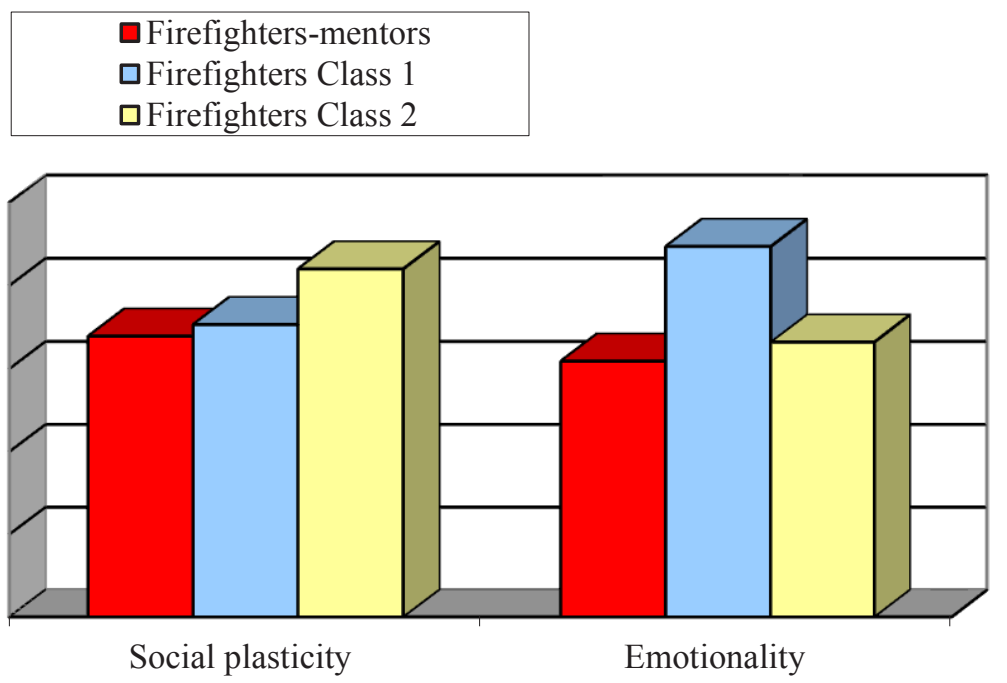


Fig. 2. Histogram of indicators of social plasticity and emotionality among firefighters of various groups.

The presented histograms reflect significant differences in the development of such properties as social plasticity and emotionality. Social plasticity is more pronounced in firefighters at the stage of preparation for the profession: they are able to easily switch in the process of communication from one person to another, and are prone to a variety of communication programs. These results can be interpreted as a manifestation of the age characteristics of class 2 firefighters: youth is characterized by flexible communication with a change of various programs and patterns.

\section{Discussion}

We can divide the activities of firefighters into three stages: preparatory, main and final. The preparatory stage includes giving an alarm, collecting personnel on the alert, following to the scene of a fire or other incident, and bringing forces and means to a state of readiness for a combat mission. The most typical conditions are severe time constraints and uncertainty of the situation (there is no complete information about the incident). Already these requirements of activity allow us to say that the tempo characteristics of a person's temperament in this case are determining why the speed of operations, the speed of motormotor acts when performing subject and communicative activities, and the speed characteristics of speech-motor acts are the most developed properties in the temperament structure of all experimental groups [1-2].

The specifics of the main stage of combat activity is that the work of firefighters is associated with a risk to life (explosions, landslides, high temperatures, toxic gases), i.e. with the presence of a large number of stress factors that cause a state of pronounced neuropsychic state (stress). Conditions this phase also imply high demands on the tempo properties of the temperament and arginate and social arginate and participatory activities, the pursuit of mental and physical labor, labor force participation, focus on the development of social activities, commitment to leadership [6-7].

Interesting results were obtained on emotionality. Class 2 firefighters and mentor firefighters have approximately similar values for the development of this indicator, while class 1 firefighters are highly emotional, which means that they are highly sensitive to the discrepancy between the planned and expected, high anxiety about work, and sensitivity to failures. High values on this scale may indicate some accentuation of these properties, which may be one of the reasons for the development of emotional burnout. We assume that low values on the scale of emotionality in class 2 firefighters may mean that this indicator is not formed in people who choose the profession of a firefighter. The very situation of professional selection involves the selection of applicants in the structure of individual properties of which emotionality has low values and is not represented as dominant in the structure of a person's personality.

As you enter the profession, master professional skills, encounter stressful situations, risk situations, and physical exertion that are characteristic of this type of activity, your emotionality changes and increases. A person begins to react to stress, which is manifested, among other things, in the development of emotional sensitivity to the discrepancy between the expected and planned, the formation of sensitivity to failures in work, and an increase in General sensitivity to stressful events. These include: death or injury of a person; a situation when it is impossible to get access to the victim; an emergency case when the rescuer is personally familiar with the victim; situations during rescue when the victim received severe burns or injuries that exclude the possibility of recovery, with the evidence of severe pain and suffering; experiencing a threat to their own life and health, etc. 
High values of the emotionality scale for representatives of the second experimental group-firefighters with 1 class category, may mean that representatives of this group have problems in emotional self-regulation. In this case, there is a need for its development, the formation of self-regulation techniques, and the formation of adaptive psychological mechanisms [12]. This circumstance is extremely important, because with difficulties in the development of emotional self-regulation, conditions for the development of emotional and professional burnout arise.

Professional burnout is a syndrome that develops against the background of chronic stress and leads to the depletion of emotional, energetic and personal resources of a working person. Professional burnout occurs as a result of internal accumulation of negative emotions without a corresponding "discharge" or "release" from them [7]. In essence, professional burnout is distress or the third stage of the General adaptation syndrome - the stage of exhaustion, and both of these factors can lead class 1 firefighters to be dismissed from the ranks of firefighters to preserve their psychophysical health. Also, conditions that arise under the influence of extreme factors, in addition to threats to human health and life, significantly reduce the success and quality of work, increase the level of psychophysiological "price" of activity, and often have a number of unacceptable sociopsychological consequences: increased staff turnover, reduced job satisfaction, deformation of personal and characterological qualities.

Low values on the scale of emotionality in the third experimental group-firefighters with 1 class category, may indicate that a high level of skill is possible with the formed mechanisms of emotional self-regulation.

\section{Conclusions}

The study allows us to draw the following conclusions:

1. similar values of the expression of temperament properties were found in three experimental groups. The results show that similar requirements on the part of professional activity contribute, on the one hand, to the professional selection of people with certain temperament properties, and on the other hand, professional development of a person deepens and improves the expression of temperament properties.

2. it was shown that the structure of professionally important qualities related to the requirements of the activity, and included certain properties of temperament, which create a specific type of personality in the structure of the professional personality. These include: tempo social arginate, arginate, social pace. Thus, we assume that these properties of temperament act as professionally important qualities at the individual level of the human system structure [15].

3. at the same time, professional development of the individual suggests that some properties become more pronounced at different stages of professional development: social plasticity is more pronounced in class 2 firefighters (the stage of preparation for the profession) compared to employees of fire formations of other categories of class; employees at the stage of professionalism are highly emotional compared to cadets and firefighters at the stage of skill.

4. High values on the emotionality scale for firefighters at the stage of professionalism may indicate that representatives of this group may have problems in emotional selfregulation that affect the development of emotional and professional burnout, which implies the organization of special psychological training aimed at psychological education and the formation of emotional self-regulation skills.

5. The results show that the properties of temperament can act as determinants that affect the effectiveness of professional activities of firefighters. 


\section{References}

1. A. Airila, Work characteristics, personal resources, and employee well-being: A longitudinal study among Finnish firefighters (Finnish Institute of Occupational Health, Helsinki, 2015)

2. D.L. Smith, Curr. Sports Med. Rep. 10, 167-72 (2011)

3. F. Perroni et al, The Open Sports Sci. J. 7(l-1, M3), 8-15 (2014)

4. Y.R. Gillani, M. Atif, J. of Pub. Adm. and Gov. 5(1), 173-181 (2015) DOI:10.5296/ jpag.v5i1.7377

5. W. Oniszczenko, Inter. J. of Occup. Med. and Env. Health 27(4), 599-607 (2014) http://dx.doi.org/10.2478/s13382-014-0287-3

6. N. Kose et al, J. of Mood Disorders (JMOOD) 6(4), 218-26 (2016) DOI:10.5455/jmood.20161230113244

7. R.M. Oosthuizen, P. Koortzen, South. Afr. Bus. Rev. 10(3) (2012)

8. B. Zawadzki et al, Encyclopedia of Personality and Individual Differences (Springer International Publishing AG, part of Springer Nature 2018) (2018) https://doi.org/10.1007/978-3-319-28099-8_2285-1

9. J. Strelau, B. Zawadzki, Activity as a temperament trait. The handbook of temperament (The Guilford Press, New York, 2012)

10. V.M. Rusalov, Temperament in the structure of human personality: differential psychophysiological and psychological studies (IP RAS, Moscow, 2012)

11. V.M. McKeever, M.E. Huff, Rev. of Gen. Psychol. 7(3), 237-250 (2013) doi:10.1037/1089-2680.7.3.237

12. W. Berger et al, Society of Psych. and Psych. Epidem. 47, 1001-1011 (2012)

13. O.P. Eliseev, Workshop on the psychology of personality (Peter, St. Petersburg, 2010)

14. A.D. Nasledov, Mathematical methods of psychological research. Analysis and interpretation of data (St. Petersburg, Speech, 2012)

15. A. Belousova, Proc. Soc. and Beh. Sci. 5 Inter. Conf. on Ed. \& Ed. Psychol. 171, 987994 (2015) DOI: 10.1016/j.sbspro.2015.01.217 